\title{
LA LLAMADA "FASE PRE-LEVANTINA" Y LA CRONOLOGÍA DEL ARTE RUPESTRE LEVANTINO. UNA REVISIÓN CRÍTICA
}

\author{
THE SO-CALLED "PRE-LEVANTINE" PHASE AND THE CHRONOLOGY OF THE \\ LEVANTINE ROCK PAINTING. A CRITICAL REVIEW
}

MIGUEL ÁNGEL MATEO SAURA (*)

\section{RESUMEN}

El rechazo de las bases en las que se sustenta la llamada "fase pre-levantina" y la discusión de los paralelos mobiliares neolíticos propuestos para el arte levantino dejan expedito el camino para su adscripción a los grupos de cazadores y recolectores epipaleolíticos.

Asimismo, los datos con que contamos sobre el proceso de transición Epipaleolítico/Neolítico, y la relación entre el estilo levantino y la pintura rupestre esquemática parecen abogar también por una cronología pre-neolítica de lo levantino, asociado a unos modos de vida no productores.

\begin{abstract}
The rejection of the principles on which the so-called "prelevantine phase" is based and the discussion about the neolithic material culture parallels for levantine art allow its attribution to Epipaleolithic groups of hunters and gatherers.

In the same way, the data on the process of transition between the Epipaleolithic and the Neolithic, and the relationship between the levantine style and the schematic rock painting seem to support a pre-neolithic chronology of the levantine art, related to non-producing ways of living.
\end{abstract}

Palabras clave: Arte levantino. Cronología. Epipaleolítico. Neolítico.

Key words: Levantine art. Chronology. Epipaleolithic. Neolithic.

(*) Santo Domingo de Guzmán, 25. Aljucer. Murcia. Correo electrónico: mateo_saura@terra.es

Recibido: 28-VIII-2001; aceptado: 16-XII-2001.

\section{INTRODUCCIÓN}

Cuando está próximo a cumplirse el primer centenario del descubrimiento en 1902 de los ciervos de la Roca dels Moros, en Cretas (Teruel) por Juan Cabré, la cronología del arte rupestre levantino sigue siendo una de las cuestiones que suscita mayor controversia en su investigación.

Si en un primer momento se le atribuye una edad paleolítica paralela a la del, por entonces llamado, "arte franco-cantábrico" y hoy sólo mantenida por algún investigador (Dams 1984), el hecho de que más tarde se adscribiera a etapas postpaleolíticas, en virtud de las profundas disonancias que existen entre ambos estilos (Hernández Pacheco, 1924; Almagro Basch, 1947; 1951; Criado y Penedo, 1989) y, más recientemente, por la documentación de un arte paleolítico repartido por toda la Península Ibérica, lejos de solucionar el problema va a suponer un importante trasiego cronológico para el arte levantino que lo lleva, según el autor que lo trate, a fechas epipaleolíticas, neolíticas e, incluso, más recientes.

La ausencia de indicadores de cronología absoluta tales como la estratigrafía arqueológica o los paralelos mobiliares llevaron a la utilización de otros criterios, de validez muy cuestionable, como son las supuestas sucesiones de color, las pequeñas variaciones tipológicas entre motivos, el estudio y comparación etnográficos o la proximidad de las pinturas a yacimientos arqueológicos para establecer una secuencia estilística y cronológica. Sin embargo, la poca fiabilidad de la mayoría de estos índices de referencia queda de manifiesto incluso en los estudios comarcales. Es cierto que en estos últimos años se han obtenido importantes avances en el campo de la datación absoluta del arte rupes- 
tre con el desarrollo de métodos como el del carbono 14 por espectrometría de acelerador de masas (C14 AMS ) que, a partir de mínimas muestras de materia orgánica, permite obtener fechas absolutas, o también mediante la técnica de la termoluminiscencia, aplicada con éxito en la cronología de materiales ricos en carbonatos como son las costras estalagmíticas en el yacimiento paleolítico de Venta de la Perra (Arias et al., 1998/99). No obstante, aunque hay que reconocer que, en verdad, suponen un destacado paso en el ámbito de la datación, no debemos olvidar tampoco que hoy por hoy ambos métodos plantean algunas limitaciones. El C14 $A M S$ tan sólo se puede emplear con un reducido tipo de representaciones, aquellas de color negro realizadas con materia orgánica, debiendo además reunir la doble condición de que el colorante sea abundante y que esté bien conservado. A ello se une que problemas de contaminación de las muestras obligan en muchos casos a tomar con prudencia las fechas obtenidas. Por su parte, la termoluniscencia, si bien permite fechar elementos bastante comunes en las cuevas y abrigos pintados como son las coladas estalagmíticas, no deja por ello de proporcionar una fecha de ese accidente del soporte y por tanto, una fecha ante quem o post quem para las propias pinturas.

También en el campo de la toma de muestras se han logrado interesantes progresos con el desarrollo de técnicas como las del plasma de oxígeno y de la fotooxidación inducida por láser, dirigidas ambas a la recuperación de materia orgánica incluida en otros soportes minerales. Sin embargo, todavía presentan como mayor inconveniente la gran cantidad de materia prima que se precisa para el análisis (Chapa, 2000).

Una vez superadas las viejas ideas paleolitistas y a la vista de los diferentes horizontes artísticos establecidos en estos últimos años, la secuencia más aceptada del arte rupestre prehistórico en la vertiente mediterránea peninsular ha quedado establecida, de forma resumida y sin solución de continuidad, en Arte Paleolítico, Arte Lineal-geométrico, Arte Macroesquemático, Arte Levantino y Arte Esquemático, al modo en que la vemos en algunas de las obras de síntesis de más reciente publicación (Beltrán, 1998; Moure, 1999).

Pero lejos de poder corroborar esta secuencia lineal, son muchos los aspectos que nos obligan a realizar matizaciones y que hacen del arte rupestre una realidad muy compleja, difícil de clasificar en esas especies de compartimentos estanco. Quizás el primer problema que surge tras la adopción de una datación postpaleolítica para el arte levantino sea el de intentar explicar el hiatus cronológico respecto al arte paleolítico, aún cuando algunos autores hayan querido ver una tradición perigordiense en las fases iniciales del levantino (Beltrán, 1968a; Ripoll, 1968) o se recurra también a otros ciclos como el aziliense para intentar llenar ese vacío. En esta línea, la definición, en su momento, de nuevos horizontes artísticos como los llamados Lineal-Geométrico y Macroesquemático contribuyeron, en principio, a salvar este problema por cuanto, dada su presunta cronología pre-levantina, suponían a la vez una fecha de partida para el propio arte levantino.

\section{LA ETAPA PRE-LEVANTINA: PLANTEA- MIENTO Y DISCUSIÓN}

En 1974 F.J. Fortea define el llamado arte linealgeométrico a partir de la relación que establece entre las plaquetas grabadas halladas en la Cueva de la Cocina (Dos Aguas, Valencia), también provista de representaciones parietales, y las superposiciones cromáticas existentes en los conjuntos de Cantos de Visera II (Yecla, Murcia), Cueva de la Araña (Bicorp, Valencia) y Abrigo de la Sarga I (Alcoy, Alicante), en donde por debajo de motivos naturalistas se disponen varios trazos aparentemente geométri$\cos$, hecho que en La Sarga ya había sido advertido por Beltrán (1970). La cronología de este nuevo horizonte lineal-geométrico, caracterizado por una decoración basada en líneas rectas que se entrecruzan formado retículas, vendría determinada por el nivel II de Cocina, datable en el Epipaleolítico geométrico, con fechas absolutas que lo encuadrarían entre finales del VI e inicios del V milenios a.C.

Posteriores descubrimientos amplían el número de motivos pintados presuntamente lineal-geométricos en el Abrigo de los Chaparros (Albalate del Arzobispo, Teruel), el Abrigo de Labarta LI (Huesca), la Balsa de Calicanto (Bicorp, Valencia) y en el Barranco de Benialí (Vall de la Gallinera, Alicante), con lo que se enriquece aún más este estilo y se perfila un poco mejor esta supuesta "fase pre-levantina” esbozada por Beltrán (1987) (Fig. 1).

Sin embargo, aunque en la abundante literatura publicada desde entonces se admite sin mayores consideraciones la existencia de este arte linealgeométrico, muchas son las dudas que se nos plantean a la hora de aceptarlo realmente como tal. $\mathrm{La}$ revisión efectuada de estos motivos pintados ha lle-

T. P., 59, n. ${ }^{\circ} 1,2002$ 


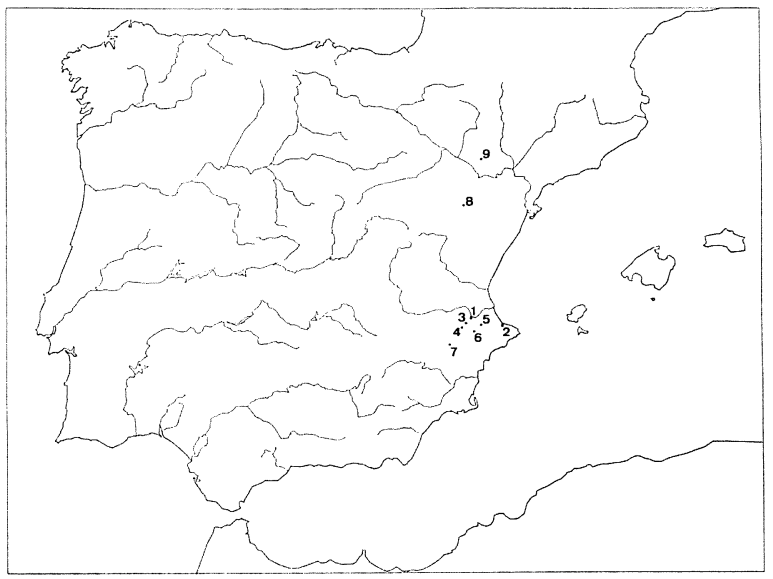

Fig. 1. Mapa de dispersión de los yacimientos propuestos como lineal-geométricos: 1. Cueva de la Cocina; 2. Cueva del Parpalló; 3. Cueva de la Araña; 4. Balsa de Calicanto; 5. Barranco de Benialí; 6. Abrigo de la Sarga I; 7. Cantos de Visera II 8. Abrigo de los Chaparros; 9. Abrigo de Labarta LI.

vado a reconsiderar su filiación estilística, modificada en la mayor parte de los casos. Así, los trazos serpenteantes hasta ese momento definidos como lineal-geométricos en los Abrigos de la Sarga se han adscrito a un ciclo artístico diferente, el llamado Macroesquemático (Hernández et al., 1988), al igual que ha sucedido con las líneas ondulantes del Barranco de Benialí (Hernández et al., 1994). En la Cueva de la Araña los motivos abstractos pertenecen al horizonte de la pintura esquemática siendo además la zona de contacto entre ellos y lo levantino tan reducida que no es posible hacer una valoración real de la misma (Hernández Pacheco, 1924), hecho que se repite con varios serpentiformes esquemáticos y un cuadrúpedo levantino en la Balsa de Calicanto. Mientras, para las figuras de Labarta LI los trabajos desarrollados por $\mathrm{M}^{\mathrm{a}}$ Josefa Calvo con fotografía de infrarrojos han revelado la superposición inversa a la hasta ahora mantenida, es decir, la de los motivos esquemáticos, en ningún caso lineal-geométricos, sobre las representaciones levantinas (Beltrán, 1999).

Por otra parte, la relación establecida entre el arte mueble de las placas grabadas y los testimonios pintados, incluidos los propios motivos de la Cueva de la Cocina ya reseñados por L. Pericot (1945), son en lo estrictamente formal, cuanto menos, discutibles. Mientras que la decoración de las plaquetas se hace por medio de la línea recta, que en ocasiones se entrecruza para formar retículas, en las figuraciones pintadas hay una mayor variedad iconográfica, pero siempre con predominio de la línea curva. De igual modo, una rápida comparación entre los propios ejemplos parietales pone de relieve una mínima coincidencia formal entre ellos. Baste comparar los signos de Cantos de Visera II con los de Los Chaparros para percibir la nula similitud en su aspecto y, a la vez, la de ambos con las plaquetas grabadas, todo lo cual hace difícil concebirlos como partes integrantes de un mismo horizonte iconográfico. De aceptarse su pertenencia a ese mismo horizonte, éste englobaría desde manifestaciones reticulares con preeminencia de la línea curva y serpentiformes como los de Cantos de Visera, hasta otros motivos en zig-zags como los de Labarta, o en "diente de sierra" como los de Los Chaparros, lo que le otorgaría una heterogeneidad manifiesta, sobre todo con relación a su supuesta vertiente mueble, mucho más reducida tipológicamente y cuyas limitaciones no se pueden explicar sólo por las diferencias en los soportes y las técnicas de ejecución (Fig. 2).

Al mismo tiempo, la inclusión en este arte linealgeométrico de conjuntos como Los Chaparros y Labarta evidenciaría una dispersión territorial quizá demasiado amplia para este estilo, cuyo germen debería estar en torno a la Cueva de la Cocina, sobre todo si tenemos en cuenta que este ha sido el único yacimiento que ha reportado elementos de arte mueble. Los trabajos desarrollados en estos últimos años en yacimientos como Botiquería dels Moros, Costalena, Els Secans o El Pontet en el Bajo Aragón, o la Cueva del Nacimiento y Valdecuevas en el Alto Segura, entre otros, han aportado numerosos datos sobre el Epipaleolítico geométrico paralelizable al de Cocina, sin que en ninguno de ellos se haya documentado un arte mueble similar, o aproximado, al de las plaquetas grabadas de este último yacimiento (1).

En este estado de cosas, la nueva interpretación de conjuntos como La Sarga, Barranco de Benialí, Cueva de la Araña, Balsa de Calicanto y Abrigo de Labarta LI, las nulas coincidencias formales entre las propias representaciones parietales y, a su vez,

(1) Las alusiones que hay a lo largo del texto a términos como Epipaleolítico o Neolítico hacen referencia, en la mayor parte de los casos, a su acepción como fase cultural, en tanto contraponen dos modelos de vida diferentes, uno depredador y otro ya productor. Por su parte, en aquellas ocasiones en las que aludamos a cuestiones tecno-tipológicas sobre materiales hallados en yacimientos de alguno de estos periodos, lo haremos en pos de mostrar la uniformidad que al respecto reflejen esos materiales referidos como apoyo a nuestras argumentaciones. 

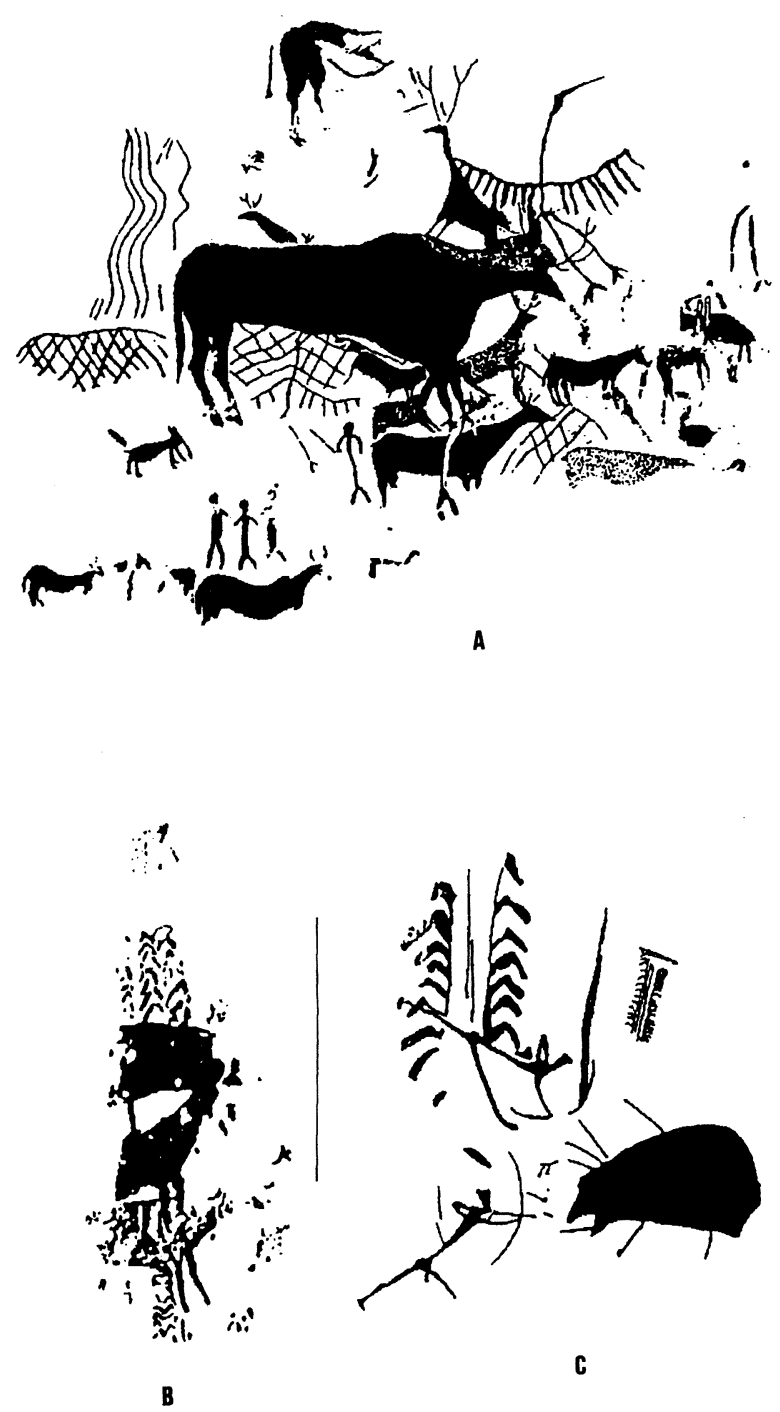

Fig. 2. Motivos esquemáticos propuestos como linealgeométricos: A: Cantos de Visera II (según J. Cabré); B: Abrigo de Labarta LI (según A. Beltrán); C: Abrigo de los Chaparros (según V. Baldellou).

de éstas con las placas grabadas y la falta de paralelos mobiliares nos llevaron hace años, coincidiendo en esta apreciación con otros investigadores (Hernández, 1992), a rechazar la existencia de un arte parietal lineal-geométrico, debiendo considerarlo si se quiere mantener su presencia como tal horizonte artístico como un arte exclusivamente mueble (Mateo, 1993, 1995). En este sentido, los mejores paralelos para las plaquetas de La Cocina los encontramos en las placas grabadas de los niveles solutrenses y magdalenienses de la Cueva del
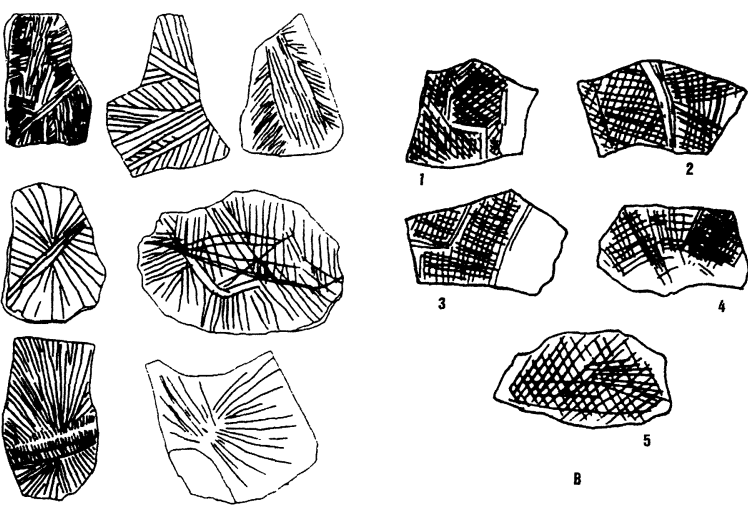

A

Fig. 3. A: placas grabadas del nivel II de la Cueva de la Cocina (según I. Barandiarán ); B: placas grabadas de la Cueva del Parpalló: 1, 2 y 3 del nivel Magdaleniense III, 4 y 5 del nivel Magdaleniense IV (según L. Pericot).

Parpalló (Pericot, 1942), decoradas también con representaciones reticulares, de tal forma que no creemos demasiado osado pensar que lo que se hace en La Cocina no es sino recoger una tradición, muy local, del Parpalló (Fig. 3).

No entramos a valorar las propias pinturas de la Cueva de la Cocina (Fig. 4), descritas por Fortea (1975) como pinturas que no son ni levantinas ni esquemáticas y sobre cuyo carácter levantino, que ya fuera intuido por Pericot (1945) cuando las relacionó con el cercano conjunto del Cinto de las Letras, sí han insistido otros autores en estos últimos años (Grimal, 1995). De confirmarse su identidad levantina, algo complicado por su poca entidad y su mal estado de conservación, sin duda serían un índice cronológico de gran valor puesto que revelarían de forma indiscutible la presencia de este estilo naturalista en fechas epipaleolíticas.

El llamado arte macroesquemático y su relación con el levantino ha sido otro de los elementos utilizados para acotar los límites cronológicos de éste último.

En 1982 M.S. Hernández y el Centro de Estudios Contestanos publican los primeros datos acerca de un nuevo tipo de arte rupestre, que ellos denominan como Macroesquemático y que otros autores nombran como Lineal-Figurativo (Aura, 1983), Contestano (Jordá, 1985), Cardial (Fortea y Aura, 1987) o Petracos (Beltrán, 1987). A los primeros hallazgos de Plá de Petracos, en Castell de Castells, le siguen otros hasta un total de diez conjuntos con los que contamos en la actualidad (Hernández et al., 1994), concentrados en la región de 

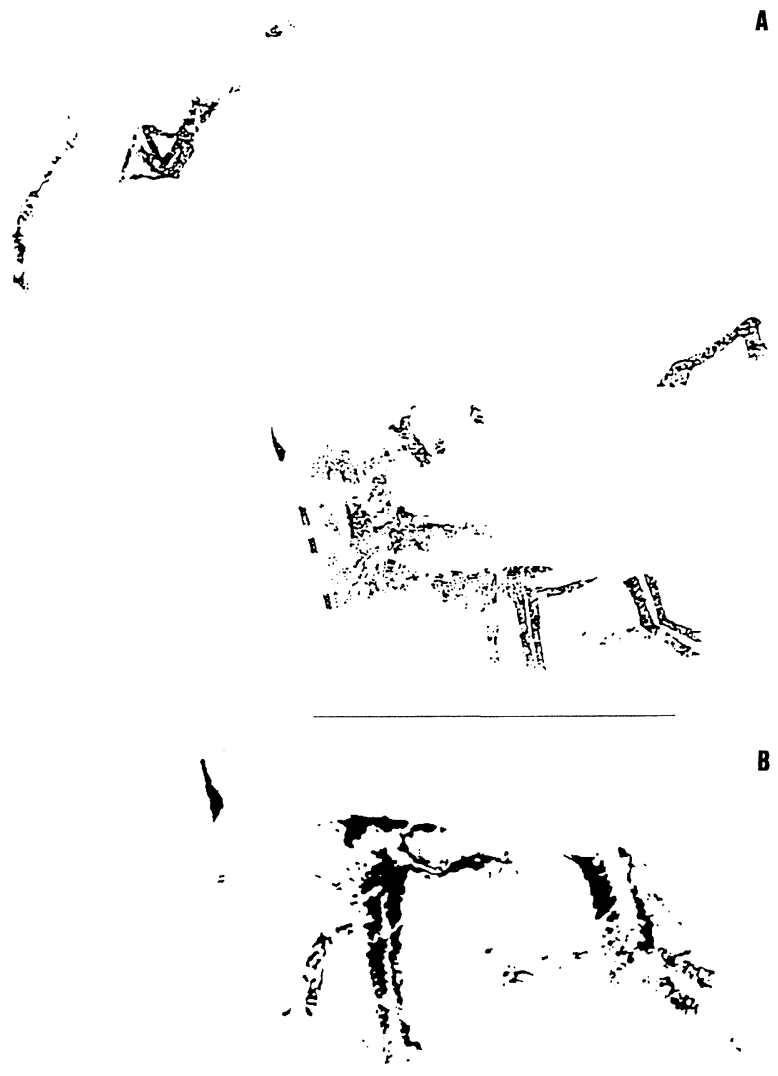

Fig. 4. Restos de las pinturas de la Cueva de la Cocina: A. según F.J. Fortea; B. según A. Grimal.

Cocentaina, en torno a las sierras de Aitana, Mariola y Benicadell.

Está caracterizado por las grandes figuras antropomorfas de rasgos esquemáticos, en actitud "orante" y con los brazos agitados en alto y, junto a éstos, por largos trazos serpentiformes. Al mismo tiempo, el estudio de materiales cerámicos de yacimientos como la Cova de l'Or de Beniarrés y la Cova de la Sarsa de Bocairente permitieron identificar una decoración de motivos antropomorfos paralelizables a algunos de los esquemas humanos propios de la pintura macroesquemática, en concreto humanos en X, Y, doble Y y de brazos levantados (Martí y Hernández, 1988). Su datación en un Neolítico antiguo, incluso con fechas radiocarbónicas de 4770 a.C. (C13 M3: $6720 \pm 380 \mathrm{BP})$ y de 4680 a.C. (C12 M2: $6630 \pm 290$ BP) en la Cova de l'Or (Martí, 1978; Martí et al., 1980), hace que el arte rupestre adopte una sincronía con esta cultura material, lo que lo asocia a las primeras comunidades de agricultores y ganaderos en la comarca.

Por su parte, la infraposición de motivos ma- croesquemáticos a representaciones levantinas en el Abrigo I de la Sarga y la ubicación de otros sobre un desconchado que ha destruido parcialmente unos serpentiformes en el Barranco de Benialí ha sido sobrado pretexto para otorgar una cronología posterior a todo el arte levantino.

Esta hipótesis se vería, a priori, corroborada con el hallazgo de decoración cerámica paralelizable a figuras levantinas en la misma Cova de l'Or (Fig. 5). En concreto, se trata de dos fragmentos de una misma vasija en los que mediante la impresión con un instrumento se han representado, por una parte la cabeza, cuernos y una porción del cuerpo de un cáprido, y por otra los cuartos traseros y la larga cola de un animal no identificable, y la cornamenta, parte de la cabeza y del cuerpo de un cérvido (Martí y Hernández, 1988). Se apunta, incluso, la existencia
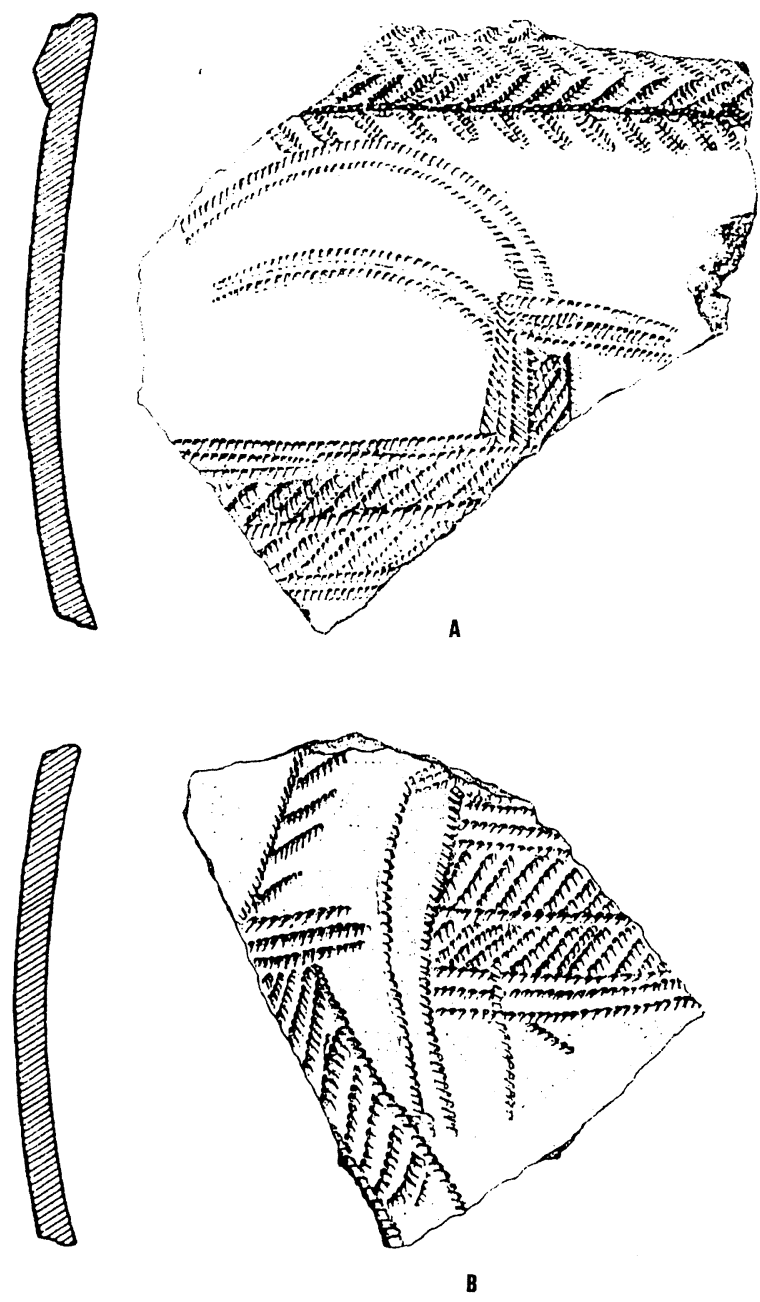

Fig. 5. Fragmentos de cerámica impresa con instrumento de la Cova de l'Or (según B. Martí y M.S. Hernández). 
de una tercera pieza cerámica que mostraría la forma de la cabeza, parte del cuerpo y las alas de un ave (Hernández, 1992). Estos materiales se sitúan estratigráficamente en un momento avanzado del Neolítico antiguo, lo que vendría a reforzar la anterioridad del arte macroesquemático y el encuadre cronológico del levantino a finales del $\mathrm{V}$ milenio a.C.

Sin embargo, somos de la opinión de que la relación establecida entre estos motivos impresos y los levantinos no es tan evidente como se ha señalado, aún cuando se pretendan justificar sus disonancias formales a partir de la rigidez y el esquematismo que imponen el soporte cerámico y la propia técnica impresa. El marcado esquematismo que rodea a las figuraciones impresas, los ángulos rectos para la cabeza o las zonas de unión del cuello y del cuerpo, las patas de los animales excesivamente simplificadas y torpes, y la forma general de las figuras, creemos que son detalles que no se pueden explicar solamente por las diferencias en la naturaleza del soporte y de los procesos técnicos seguidos (Mateo y Carreño, 2000), y que los alejan de los conceptos de representación propios del estilo levantino.

Por otro lado, todos los fragmentos cerámicos con decoración se engloban en el mismo contexto cultural de un Neolítico antiguo, en concreto en el definido por Bernabeu (1988) para la cueva como Neolítico IA, lo que explica no sólo que las figuras impresas con instrumento muestren una forma de cubrir el espacio interior de la figura con ritmos idénticos enmarcados en líneas horizontales y verticales, lo que a su vez contrasta con la imagen plana levantina (Alonso y Grimal, 1999), sino que coincida en este concepto de representación con los otros motivos impresos cardiales. De igual manera, el hecho de que no haya representaciones parietales zoomorfas dentro del estilo macroesquemático creemos que no es razón suficiente para desligarlos de ese contexto en favor de su vinculación con la pintura levantina.

Acerca de las superposiciones de motivos parietales levantinos sobre macroesquemáticos, si consideramos que lo macroesquemático abarca por el momento un espacio geográfico muy concreto y limitado, también podemos pensar que estas sobreposiciones pueden ser evidencia de que en este área ambos estilos, o bien convivieron durante un período de tiempo determinado, o también que el estilo levantino tuvo una pervivencia mayor. Sea una u otra posibilidad y dada la cronología neolítica muy temprana del horizonte macroesquemático, creemos que no sería disparatado plantear la posible filiación del arte levantino con los grupos epipaleolíticos, bien como tales grupos epipaleolíticos o también como grupos retardatarios no neolitizados.

Desde luego, lo que no parece que debamos aceptar es que el macroesquematismo sea el punto de partida de dos concepciones artísticas tan distintas como son la levantina y la esquemática, como algún autor ha apuntado (Jordá, 1985). Al margen de las precisiones cronológicas reseñadas, resulta difícil admitir que el arte macroesquemático fuese el origen de este arte naturalista cuando ambos estilos muestran características iconográficas tan dispares y nada invita a pensar que el trasfondo social y religioso que podemos intuir detrás del macroesquematismo guarde relación con aquel que apreciamos en la pintura levantina.

\section{ARTE LEVANTINO Y PINTURA ESQUEMÁTICA}

Si importante se nos presenta la relación existente entre el estilo levantino y otros ciclos artísticos como el macroesquemático, mayor es, si cabe, el interés que desprende su relación con otro de los horizontes culturales más destacados de la Prehistoria peninsular, la pintura rupestre esquemática.

Diversas propuestas cronológicas se han mantenido a lo largo del tiempo sobre la pintura esquemática. Considerado, en un principio, su carácter funerario por la relación que parecía existir entre abrigos pintados y sepulcros megalíticos (Obermaier, 1916; Breuil, 1933/35; Cabré, 1941), la representación de motivos esquemáticos en otros contextos pronto obliga a ampliar los criterios a la hora de buscarle un origen y significación. Por otro lado, cuando nos referimos a la pintura esquemática estamos aludiendo, quizás indirectamente, a un fenómeno mucho más amplio que podríamos denominar bajo el epígrafe de Arte Esquemático, bajo el cual se engloban diversos horizontes culturales e iconográficos, en ocasiones muy dispares y sin relación alguna, cuyo único rasgo común es el de compartir el esquema y la abstracción como forma gráfica de expresión de un contenido, muy probablemente, con una intención religiosa.

En esa especie de cajón de sastre en que se puede convertir el Arte Esquemático englobamos las manifestaciones pintadas parietales, no ajenas a particularidades regionales y en estrecha relación

T. P., 59, n. ${ }^{\circ} 1,2002$ 
con el sustrato cultural de cada zona, pero también el llamado arte megalítico, con evidentes relaciones con aquélla, y el horizonte de las insculturas y petroglifos, que conforman un ciclo artístico con personalidad propia, al margen del otro esquematismo de la pintura o el grabado.

Centrándonos en la pintura, hemos de admitirla como una realidad muy compleja, con unos límites cronológicos amplios y que, con adaptaciones, pervive en diferentes contextos culturales tal y como denotan los paralelos mobiliares. Hay motivos que, como los denominados ídolos, parecen tener un desarrollo más acusado en una etapa concreta, pero otros se muestran, con o sin variaciones tipológicas, desde los orígenes hasta los momentos finales. Sucede, por ejemplo, con las figuras conocidas como ramiformes que encontramos en un Neolítico antiguo en la Cova de l'Or (Martí y Hernández, 1988), en un Neolítico final en vasijas cerámicas de la Carigüela del Piñar (Granada), asociados a niveles calcolíticos en Millares (Almería), a campaniforme en el Cerro de la Virgen (Granada) y en un horizonte de transición del Eneolítico al Bronce I en el Castillarejo de los Moros (Valencia) (Acosta, 1984).

Durante mucho tiempo, la hipótesis más generalizada ha sido la de vincular el nacimiento de este esquematismo peninsular con la llegada de influencias exteriores procedentes del Mediterráneo oriental y traídas por los pueblos prospectores de metal, lo que situaba a la pintura esquemática en un horizonte cronológico que arrancaba en el Eneolítico y se mantenía a lo largo de la Edad del Bronce, con pervivencias incluso, más tardías (Beltrán, 1983, 1998). Los paralelismos entre los motivos pintados y la cultura material de esos contextos calcolíticos apoyaban esta idea. También había autores que se desmarcaban un tanto de esta postura general y consideraban este esquematismo como una resultante de la propia evolución final del estilo levantino, al que, no obstante, se suman algunas aportaciones foráneas de tipo religioso y espiritual relacionadas, a su vez, con la cultura dolménica (Ripoll, 1983).

Sin embargo, hace años que el hallazgo de materiales cerámicos neolíticos con una decoración paralelizable a las figuras pintadas llevó a pensar en un origen anterior para esta pintura esquemática (Marcos, 1981). Desde entonces, la documentación de nuevas muestras ha venido a confirmar esa sospecha (Fig. 6). En 1984, P. Acosta aporta un interesante repertorio de motivos de arte mueble de

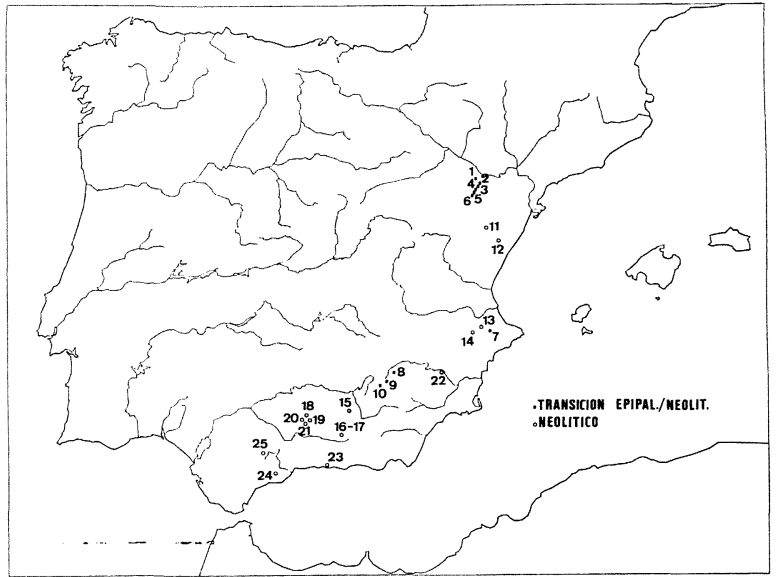

Fig. 6. Yacimientos con niveles de transición Epipaleolítico/Neolítico, y neolíticos: 1. El Serdá; 2. Abrigo de Costalena; 3. El Pontet; 4. Abrigo de Secans; 5. Cova del Llop; 6. Botiquería dels Moros; 7. Tossal de la Roca; 8. Molino de Vadico; 9. Cueva del Nacimiento; 10. Valdecuevas; 11. Cueva Fosca; 12. Cueva Matutano; 13. Cova de l'Or; 14. Cova de la Sarsa; 15. Cueva de la Carigüela; 16. Cueva de la Mujer; 17. Cueva del Agua del Prado Negro; 18. Cueva de los Murciélagos; 19. Cueva de la Murcielaguina; 20. Cueva del Muerto; 21. Cueva Negra; 22. Abrigos del Pozo; 23. Cueva de Nerja; 24. Cueva de los Botijos; 25. Cueva de las Goteras.

datación neolítica, entre ellos antropomorfos en la Cueva del Agua del Prado Negro (Granada), esteliformes en la Cueva de la Carigüiela (Granada), Sima del Carburero (Granada), Cueva de la Mujer (Granada), Cueva de Nerja (Málaga) y Cueva de los Botijos (Málaga), ramiformes en Cueva de la Carigüela, y motivos triangulares en Carigüela y Cueva de las Goteras (Málaga). A estos se van sumando con el tiempo otros ejemplos, como son un alisador de la Cueva de la Murcielaguina (Córdoba) con un cuadrúpedo grabado de un Neolítico medio-final (Gavilán, 1985), una vasija de esta misma cueva con soliforme impreso, líneas horizontales y verticales entrecruzadas y puntos impresos, un fragmento cerámico con cápridos de la Cueva de Nerja, un esteliforme de la Cueva de los Mármoles (Córdoba), un pectiniforme grabado en un fragmento de la Carigüela del Piñar, y trece fragmentos de las cuevas de Los Murciélagos, Muerto y Negra, las tres en Córdoba, con representaciones de esteliformes, líneas verticales y horizontales (Gavilán, 1989; Mas, 2000).

También la Comunidad Valenciana ha aportado materiales neolíticos con decoración esquemática paralelizable a la pintada en los abrigos rocosos. En 
la Cova de l'Or y en la Cova de la Sarsa diversos fragmentos cerámicos muestran motivos esteliformes, con y sin círculo, algunos antropomorfos, ramiformes y, con menor seguridad en su atribución cronológica, tres representaciones zoomorfas incisas en un fragmento cerámico encuadrable en el IV milenio a.C. (Martí y Hernández, 1988).

En este contexto debemos reseñar la fecha radiocarbónica obtenida en los Abrigos del Pozo de Calasparra (Murcia), cuyas paredes están decoradas con más de una treintena de motivos esquemáticos (Mateo, 1999) y en donde un nivel neolítico antiguo en el que se recogieron restos de pigmento ha dado la fecha de $6260 \pm 120 \mathrm{BP}(\mathrm{I}-16,783=4310$ a.C. $)$ (Martínez, 1994).

Dados estos paralelos mobiliares y la temprana cronología neolítica que de ellos se desprende para parte del código esquemático, hace tiempo que relacionamos su nacimiento con el nuevo sistema económico productor que se va implantando y en donde la pintura parietal sería la forma de expresión de una espiritualidad estrechamente unida a las nuevas formas de vida (Mateo, 1991). Se inicia así un proceso continuo de formación de ese código esquemático en el que el sustrato indígena debió jugar un papel destacado, sobre todo si tenemos en cuenta que algunas zonas donde arraigó este arte esquemático también existe otro tipo de arte, el levantino, desarrollado quizás con una importante intención religiosa. Si como parece apropiado pensar, la pintura esquemática constituye la expresión plástica de las primeras comunidades productoras, aunque su desarrollo en el tiempo le hace llegar hasta fechas más recientes, la consecuencia inicial que de ello se deriva es la disociación del arte levantino de esos mismos grupos neolíticos. No sería lógico que un mismo grupo social tuviera como propias dos corrientes de expresión tan dispares.

De otra parte, que la pintura esquemática tuviera su punto de partida en el horizonte macroesquemático, tal y como diversos investigadores han propuesto (Jordá, 1985; Martí y Hernández, 1988), es una cuestión que hoy por hoy no podemos descartar por completo, pero si en la zona nuclear del estilo macroesquemático las fechas absolutas sitúan el Neolítico antiguo ya bien entrado el $\mathrm{V}$ milenio a.C., recordemos que esta etapa se fecha en la Cova de l'Or en 4770 a.C. y 4680 a.C., en otros lugares las cronologías conocidas para esta etapa son muy anteriores. Es el caso, entre otros, de la Cueva Ma-

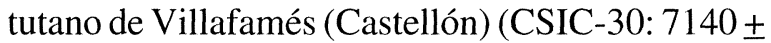
150 BP $=5190$ a.C.), Cueva Fosca de Ares de
Maestre (Castellón) (CSIC-353: $7640 \pm 100 \mathrm{BP}=$ 5690 a.C.; CSIC-357: $7210 \pm 70 \mathrm{BP}=5260$ a.C.) o de la propia Cueva de Nerja (Málaga) (GAK 8974: $7890 \pm 170 \mathrm{BP}=5940$ a.C.; GAK 8973: $7160 \pm 180$ $\mathrm{BP}=5210$ a.C.) (López, 1988), que recordemos ha aportado paralelos cerámicos a los modelos esquemáticos pintados (Acosta, 1984).

Otras veces las fechas obtenidas se aproximan mucho a las de la cueva alicantina. Situados en el Bajo Aragón, en El Pontet, en Maella (Zaragoza), un nivel de transición Epipaleolítico/Neolítico se data en 4420 a.C. (GrN-14241: $6370 \pm 70$ BP) (Mazo y Montes, 1992), y en el Abrigo de Costalena, también en Maella, un momento inmediatamente anterior a la aparición de la cerámica da la fecha de 4470 a.C. (GrN-14098: $6420 \pm 250$ BP) (Barandiarán y Cava, 1989). Por su parte, en el Alto Segura contamos con el citado nivel neolítico de los Abrigos del Pozo de Calasparra con su cronología de 4310 a.C. (Martínez, 1994) y con la Cueva del Nacimiento, en Pontones, en donde la cronología obtenida sobre un nivel del Neolítico medio es incluso más antigua que las reconocidas para la Cova de l'Or, 4830 a.C. (GIF-1368: 6780 BP no calibrado) (Rodríguez, 1979). Mientras, en la Cueva de los Murciélagos de Zuheros (Córdoba), con paralelos mobiliares esquemáticos, el Neolítico medio se data ya en 4240 a.C. (CSIC-54: $6190 \pm 130$ BP) (Muñoz, 1972). Aún cuando tomáramos con cierta cautela la fecha del yacimiento giennense de $\mathrm{Na}$ cimiento, las otras dataciones no arrojan, a nuestro entender, un margen de tiempo suficiente que explique los profundos cambios que en los ámbitos de lo mental, cultural y religioso deberían conducir desde lo macroesquemático a lo esquemático. Teniendo en cuenta además las notables diferencias que existen entre las iconografías de ambos estilos y considerando que su único punto en común es el tener a la abstracción y al esquema como formas de expresión, quizás no sea descabellado desvincular el origen de uno del otro.

La pronta documentación de superposiciones de motivos esquemáticos sobre otros levantinos en conjuntos como la Cueva de la Vieja de Alpera en1910 (Breuil et al., 1912) o los Cantos de Visera de Yecla en 1912 (Cabré, 1915) sirvió para proponer una cronología posterior a este esquematismo, en ocasiones considerado como una etapa final y degenerada en la forma del propio estilo levantino. Posteriores hallazgos ampliaron el número de casos en los que se advierten esas sobreposiciones de motivos, entre ellos Cañada de Marco de Alcaine

T. P., 59, n. ${ }^{\circ} 1,2002$ 
en1965 (Ortego, 1968), Molino de Juan Basura de Nerpio en 1968 (García y San Miguel, 1975) o ya más recientes, la Cueva de Regacéns en Huesca (Baldellou, 1983), el abrigo de Les Torrudanes en La Vall d'Ebo y el Barranc de la Carbonera II en Beniatjar (Hernández et al., 1988), la Hoz de Vicente en Minglanilla (Martínez y Díaz-Andreu, 1992) o el mencionado Abrigo de Labarta LI (Beltrán, 1999), entre otros, que vendrían a confirmar esta secuencia (Fig. 7).

En principio, estas superposiciones se convierten en un índice cronológico de gran valor por cuanto, al margen de que pueden confirmar nuestra idea antes expuesta, se presentan como una fecha ante quem para el propio arte levantino. A estos ejemplos habría que añadir también aquellos paneles en los que conviven representaciones de ambos estilos sin que esté uno por encima del otro, manifestando con ello un respeto hacia lo pintado con anterioridad.

Sin embargo, el registro de sobreposiciones inversas, de representaciones levantinas sobre esquemáticas, pone de manifiesto la existencia de una etapa de convivencia de ambos horizontes culturales, lo que nos obliga a matizar esa aparente posterioridad de lo esquemático respecto de lo levantino. Con una especial focalización de los ejemplos en el núcleo del Alto Segura, en el Abrigo del Barranco Bonito de Nerpio (Mateo y Carreño, 1997) un trazo y restos de lo que pudiera ser un cuadrúpedo cubren parte de la cabeza de un animal esquemático más grande en Solana de las Covachas IX, también en Nerpio (Alonso y Grimal, 1996), un cérvido reconvertido más tarde en cáprido se sobrepone a un esquema humano simple, y algo más alejado, en la Tabla del Pochico de Aldeaquemada (López Payer, 1988), es un cuadrúpedo de formas desmañadas el que se superpone a cinco trazos verticales. Fuera de este área, también vemos cómo en el Barranc de la Palla de Tormos (Hernández et al., 1988) un cánido levantino cubre parcialmente dos zig-zags horizontales; en Cantos de Visera de Yecla (Cabré, 1915) son varios cuadrúpedos los que afectan a una figura esquemática de zancuda y varios signos reticulares; en la Cueva de la Araña de Bicorp (Hernández Pacheco, 1924) apreciamos el contacto entre la cornamenta de un cérvido levantino y un zig-zags esquemático, aunque en verdad resulta problemático precisar la prioridad en la ejecución; en el panel 2 del abrigo V del Racó de Gorgori en Castell de Castells (Hernández et al., 2000) es una barra levantina, asociada a puntos también levantinos, la que se sobrepone a una barra vertical esquemática y en la

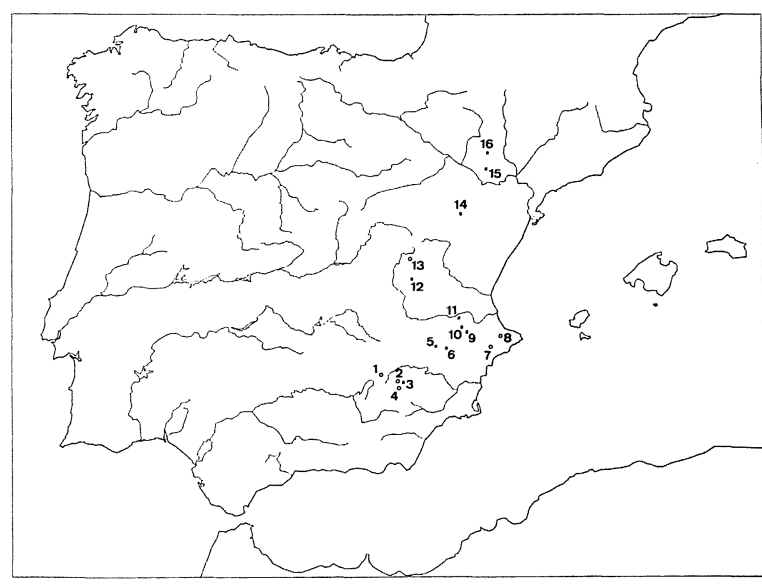

Fig. 7. Conjuntos de arte rupestre con superposiciones entre los estilos levantino y esquemático: 1 . Tabla del Pochico; 2. Barranco Bonito; 3. Molino de Juan Basura; 4. Solana de las Covachas; 5. Cueva de la Vieja; 6. Cantos de Visera; 7. Racó de Gorgori V; 8. Barranc de la Palla; 9. Barranco de les Torrudanes; 10. Barranc de la Carbonera II; 11. Cueva de la Araña; 12. Hoz de Vicente; 13. Cueva del Tío Modesto; 14. Cañada de Marco; 15. Abrigo de Labarta LI; 16. Cueva de Regacéns.

Cueva del Tío Modesto en Henarejos (Hernández et al., 2000) es un cáprido el que lo hace sobre varios trazos verticales esquemáticos.

\section{UNA PROPUESTA DE MODELO}

Llegados a este punto y con el panorama general esbozado, en el que hemos rechazado la existencia de un arte parietal lineal-geométrico de edad epipaleolítica, se han matizado las relaciones entre el arte levantino y los horizontes artísticos macroesquemático y de la pintura esquemática, y, asimismo, se ha justificado la cronología neolítica para los inicios de esta última en virtud de los paralelos mobiliares, cabría plantear pues la cuestión de la adscripción cultural y cronológica de los grupos autores del arte levantino.

Tomemos como punto de partida para nuestra valoración crítica la hipótesis desarrollada por Fortea y Aura (1987), destacada por las repercusiones que en otros investigadores ha tenido. Para estos autores, a finales del VI milenio a.C. se produce la génesis de un proceso artístico iniciado con un tímido arte de raíz epipaleolítica, el lineal-geométrico, que llega a imbricarse con otro arte ex novo, el macroesquemático, asociado a su vez a las primeras ideas neolíticas. Este arte macroesquemático 
será también el punto de partida del arte levantino, idea ya expresada por Jordá (1985), actuando de estímulo la extensión del proceso de neolitización hacia el interior. Con ligeras matizaciones, este planteamiento general es aceptado por Martí y Hernández (1988), para quienes el arte levantino surge como medio de expresión artístico del proceso de cambio cultural que sufren las comunidades epipaleolíticas inmersas en pleno proceso de neolitización.

No obstante, creemos que esta hipótesis, sustentada fundamentalmente en los tres pilares sobre los que hemos reflexionado, no es más que un intento de encajar las distintas piezas del puzzle que constituyen los diversos estilos artísticos que se manifiestan en una zona muy concreta como es el área alicantina de Cocentaina. Por nuestra parte, una vez cuestionados tanto la existencia de un arte epipaleolítico lineal-geométrico al modo en que éste fue planteado como los supuestos paralelos mobiliares de cerámicas neolíticas con la pintura levantina, no vemos mayores inconvenientes en relacionar el arte levantino con los grupos epipaleolíticos geométricos, lo que en parte coincidiría con los postulados de F.J. Fortea o M.S. Hernández, entre otros, pero considerándolo como la manifestación de la religiosidad propia de estos grupos de cazadores y recolectores y no como respuesta final a un proceso de aculturación.

En este sentido, algunos de los trabajos que han sustentado esta idea de la neolitización como origen y motor de la pintura rupestre levantina pueden ser, al mismo tiempo, muy reveladores acerca de su existencia en fechas ya anteriores. Si las formulaciones de Fortea (Fortea y Aura, 1987) o Hernández (Martí y Hernández, 1988) se apoyan en los supuestos paralelos mobiliares levantinos y en la cuestionable sucesión temporal arte macroesquemático-arte levantino, otros trabajos como el de Galiana (1992) introducen como elemento de referencia el contexto arqueológico de las pinturas y su posible relación con las mismas.

En verdad, el establecimiento de una correlación entre pintura rupestre y yacimientos arqueológicos próximos no es algo del todo punto novedoso ya que con mayor o menor acierto es un recurso cronológico empleado desde fecha muy temprana en el estudio del arte rupestre (Cabré, 1915; Fortea, 1973, 1975; Aparicio, 1977; Beltrán, 1985; Utrilla, 1986/87). Por su parte, Galiana (1992) tras realizar una clasificación tripartita de los tipos humanos representados y fijar una correspondencia con los yacimientos existentes en el entorno de los abrigos pintados de las cuencas de los ríos Ebro (Bajo Ebro), Martín, Guadalope y Matarraña, llega a la determinación de que tan sólo se puede afirmar con cierta autoridad que el grupo III, integrado por figuras que tienden a la esquematización, son atribuibles a asentamientos del Neolítico final y Calcolítico por ser de estos periodos los únicos yacimientos documentados en las cuencas fluviales donde se encuentra ese grupo III. Hemos de suponer que el criterio de adscripción se completa con el hecho de que en torno a los otros ríos sí se documentan tanto figuras humanas de los otros dos grupos determinados como yacimientos arqueológicos epipaleolíticos y del Neolítico inicial. Asimismo, dado que esta asociación sólo se observa en cuencas interiores, las de los ríos Guadalope y Martín, cabría pensar que el arte rupestre está relacionado con el proceso de neolitización de estas zonas interiores (Galiana, 1992). Vemos, pues, cómo sus deducciones, aunque obtenidas por vía diferente, coinciden con las expuestas por otros investigadores.

Sin embargo, un detenido análisis de los mismos datos aportados nos conduce a la discrepancia. Una cuestión previa en un estudio de este tipo sería excluir, en la medida de lo posible, que la ausencia de yacimientos anteriores al Neolítico final en torno a los ríos Guadalope y Martín se deba a un vacío en la investigación, para después aceptar también que la clasificación tipológica de los humanos, muy subjetiva, respeta una sucesión cronológica lineal entre los tres grupos establecidos, lo que es muy discutible. No obstante, admitamos ambas premisas. Pero si el grupo III tiene una filiación en el Neolítico final, los grupos I y II, ¿qué adscripción cultural deben tener? Los tres grupos están presentes en esas cuencas interiores, en ocasiones con porcentajes muy superiores de los grupos I y II. En el río Martín el grupo I supone el 22,4\%, el II el 43,8\% y el III un 33,6\%. En el río Guadalope la situación es más significativa ya que mientras que el grupo III engloba tan sólo al $12,1 \%$ de representaciones, el II lo hace con el $36,5 \%$ y el grupo I con el $51,2 \%$. Al mismo tiempo, en las cuencas del Bajo Ebro y Matarraña se documentan los grupos I y II, no así el III, y se registran asentamientos desde el Epipaleolítico, por lo que si se aplica el criterio precedente, estos grupos I y II se deben asociar a yacimientos anteriores al Neolítico final, ¿quizás los epipaleolíticos?

Tampoco se entiende muy bien que algunos ya-

T. P., 59, n. ${ }^{\circ} 1,2002$ 
cimientos como el Plano del Pulido, en el que sólo se había documentado en prospecciones superficiales una industria lítica de geométricos, en concreto un trapecio con retoque abrupto y un microburil, y ninguna evidencia de producción, se pueda englobar, sin mayores consideraciones, en el grupo de los asentamientos neolíticos con geométricos a fin de relacionar con él las pinturas levantinas "clásicas" de la covacha, o la Roca dels Moros de Calapatá, en donde la evidencia material es aún menor, una raedera de cuarcita con retoque de doble bisel, que se encuadra en un momento del Neolítico final, o quizá ya Eneolítico, con grandes foliáceos de base cóncava (Utrilla, 1986/87). En otras ocasiones, las asociaciones entre arte rupestre y cultura material son un tanto más gratuitas. Sucede con los conjuntos de Los Chaparros y Los Estrechos, ambos en Albalate del Arzobispo. Mientras que a Los Chaparros por su carácter levantino se le agregan varios enterramientos eneolíticos presentes en los barrancos vecinos de La Hoz y La Valdoria, con las pinturas de Los Estrechos, de estilo esquemático, se relaciona una punta de flecha metálica (Utrilla, 1986/ 87), sin que haya un criterio claro para así hacerlo.

Todo esto nos debe llevar a actuar con suma cautela a la hora de formular propuestas, máxime cuando la conexión entre arte rupestre y registro arqueológico se convierte en un recurso arriesgado precisamente por carecer de elementos objetivos de asociación.

Por otro lado, sobre la caracterización cultural de los artistas levantinos tampoco podemos dejar de lado el hecho de que en todo el conjunto de representaciones pintadas no encontramos ninguna referencia explícita a actividades de producción (Mateo, 1992, 1996), ni de agricultura ni de domesticación, aunque en verdad hemos de reconocer que no es este un dato concluyente por sí mismo.

Las composiciones presentadas como ejemplo de labores de agrícolas, al modo en que las vemos en el Abrigo del Ciervo de Dos Aguas (Jordá y Alcácer, 1951) o el Barranco del Pajarejo de Albarracín (Almagro Basch, 1960), pueden ser perfectamente admitidas como testimonios de tareas de recolección de plantas o tubérculos, mientras que en los casos referidos a la domesticación y monta convergen circunstancias variadas que invalidan esa caracterización. En ocasiones se trata de escenas en las que cabría hablar de caza a lazo, como sucede en el Abrigo de Selva Pascuala de Villar del Humo (Beltrán, 1968b), y otras veces son simplemente representaciones no levantinas, bien esque- máticas, como pasa en la Cañada de Marco de Alcaine (Beltrán y Royo, 1996) o en el Abrigo de los Borriquitos de Alacón (Beltrán y Royo, 1998), o ya de cronología histórica, como el archiconocido jinete con casco del abrigo X del Cingle de la Gasulla de Ares del Maestre (Ripoll, 1962) de adscripción muy posiblemente ibérica.

Suele ocurrir con frecuencia que, por exceso de celo $o$ ante la falta de análisis exhaustivos, se asigne la etiqueta de levantino a determinadas representaciones que a todos los efectos no lo son. A veces se trata de representaciones que imitan lo levantino, por lo general cercano en el espacio, y claro ejemplo puede ser el llamado abrigo III del Barranco de los Grajos de Cieza (Salmerón y Lomba, 1995), pero en otras ocasiones son sencillamente conjuntos enteros o figuras aisladas que, respondiendo a una motivación variada que casi siempre se nos escapa, sólo imitan de lo propiamente levantino el carácter narrativo que lo envuelve con el fin de emitir un mensáje concreto. Este es el caso de las pinturas funerarias eneolíticas de las Cueva de la Peña Rubia de Cehegín (Beltrán y San Nicolás 1988), de los cinco lagomorfos exageradamente naturalistas del Abrigo de Charán en Moratalla (Mateo y Bernal, 1999) o del equino de la Cueva de las Arañas del Carabasí de Santa Pola (Ramos, 1982) que muestra convencionalismos estéticos muy próximos a lo que conocemos de las representaciones ibéricas.

El arte levantino es un horizonte artístico bastante uniforme tanto en sus contenidos como en sus procedimientos técnicos, lo cual no excluye que haya particulares conjuntos o figuras que nos planteen una duda razonable y sobre los que siempre habrá que extremar la prudencia. Aún así, el arte levantino presenta una serie de caracteres propios que definen un perfil muy concreto que le otorgan homogeneidad.

Además, la hipótesis de la neolitización como causa del nacimiento del arte levantino no deja de plantear una situación un tanto paradójica. Durante algunos miles de años los grupos de cazadores y recolectores habrían mantenido unos modos de vida que no suscitaron la necesidad de crear una iconografía religiosa, desde luego el tantas veces referido estilo lineal-geométrico, de haber existido, no cubriría esas expectativas por lo exiguo de su desarrollo, para luego, súbitamente, al entrar en contacto con las primeras ideas neolíticas, a las que no olvidemos van aparejados unos conceptos artísticoreligiosos muy distintos basados en el esquema y el 
símbolo, surgir como de la nada y ante la necesidad, el espectacular arte narrativo y naturalista levantino, suponemos que con la intención, tal y como se ha propuesto en alguna ocasión (Llavori, 1988/89), de convertirse en salvaguarda de ese modus vivendi depredador.

Pero los datos con que contamos sobre el proceso de neolitización de las comunidades epipaleolíticas parecen indicar que en modo alguno se trató de un cambio traumático, sino más bien al contrario, de un lento y largo periodo de convivencia e intercambio entre estos grupos de cazadores y recolectores con los grupos neolíticos.

Diversos yacimientos bajoaragoneses arrojan bastante luz sobre el tema (Fig. 6). En Botiquería dels Moros de Mazaleón (Teruel) y en el Abrigo de Costalena en Maella (Zaragoza) se documenta la presencia de cazadores y recolectores que sobre sus bases técnicas y culturales epipaleolíticas van a recibir algún elemento neolitizador, en concreto la cerámica, sin que ello suponga modificar sustancialmente sus formas de vida. Con unas fechas absolutas de los niveles epipaleolíticos de 5600 a.C. (Ly-1198: 7550 \pm 200 BP) en Botiquería y de 4470 a.C. en Costalena, la neolitización de estos grupos no se va a producir por un repoblamiento tras una etapa de abandono, sino por la llegada espaciada y poco intensa de puntuales rasgos tecnológicos y culturales (Barandiarán y Cava, 1989). Es ésta una situación que vemos repetida en El Pontet, en Mae1la (Mazo y Montes, 1992), en donde un nivel de transición Epipaleolítico/Neolítico fechado en 4420 a.C. y caracterizado por una industria lítica de triángulos con retoque abrupto, mayoritarios frente a los trapecios, muestra también los primeros vestigios cerámicos. Por debajo, hay un nivel epipaleolítico datado en 5390 a.C. (GrN-16313: $7340 \pm 70$ $\mathrm{BP})$, con una industria lítica de trapecios con retoque abrupto, y por encima, un doble nivel neolítico, con fecha de 3500 a.C. (GrN-14240: $5450 \pm 290$ $\mathrm{BP}$ ), con cerámica cardial y triángulos de doble bisel el primero, y con cerámica con cordones y formas trapezoidales en lo lítico el segundo.

En el Abrigo de Secans, en Mazaleón (Rodanés, 1991), el material lítico epipaleolítico es comparable al de Botiquería y Costalena, y un nivel neolítico aporta unos pocos trozos cerámicos como elemento exótico. Esta misma secuencia la documentamos en otros yacimientos como la Cova del Llop en Mazaleón (Mazo y Montes, 1987) y en el Serdá de Fabara (Barandiarán y Cava, 1985).

Más al Sur, en el Tossal de la Roca de Vall
d'Alcalá (Alicante) (Cacho, 1986), sobre un nivel epipaleolítico con geométricos se sobrepone otro nivel ya propuesto como Neolítico al aparecer varios fragmentos de cerámica cardial. No obstante, en ambos niveles, los restos óseos de fauna indican una continuidad manifiesta, con predominio del ciervo y la cabra hispánica.

Por su parte, en el núcleo sureño del Alto Segura el cuadro general es muy similar (Mateo, 1997/ 98). En tres yacimientos se han desarrollado trabajos sistemáticos de excavación y en todos los casos los datos obtenidos confirman la evolución conocida en el Bajo Aragón.

En la Cueva del Nacimiento los primeros sondeos realizados en 1972 y 1974 (Rodríguez, 1979), completados con posteriores trabajos (Asquerino y López, 1981), documentaron cuatro etapas de habitación. Un nivel más antiguo, propio de un horizonte del Paleolítico superior, proporcionó restos de un hogar e industria lítica de raspadores, buriles y hojás con y sin retoque, fechándose en 9250 a.C. (GIF-3472: 11200 BP no calibrado) El nivel B, con restos de un hogar e industria lítica ya epipaleolítica de geométricos y microláminas, ha dado la fecha de 5670 a.C. (GIF-3471: 7620 BP no calibrado) (Rodríguez, 1979). Por último, el nivel A, considerado como Neolítico, presenta dos fases distintas, una más antigua, del Neolítico medio, que aporta una industria lítica de tipo laminar de tradición epipaleolítica, con hojas con o sin retoque, restos cerámicos decorados con impresiones y digitaciones y algunos restos óseos de fauna salvaje y doméstica, y una segunda fase, del Neolítico final, con restos cerámicos lisos y con porcentajes superiores de los restos óseos de fauna doméstica sobre la salvaje. Estos niveles neolíticos se han fechado en 4830 a.C. (Rodríguez, 1979) y 3540 a.C. (GIF-5422: $5490 \pm$ $120 \mathrm{BP}$ ) el primero, y en 2040 a.C. (GIF-5421: $3990 \pm 110$ BP) el atribuido al Neolítico final (Asquerino y López, 1981).

En Valdecuevas su excavador estableció también varias fases de ocupación, coincidentes a grandes rasgos con las definidas en Nacimiento (Sarrión, 1980). Sobre un nivel epipaleolítico con una industria en la que sobresalen los denticulados y las hojas, se sitúa un segundo nivel, adscrito al Neolítico, en el que se documentan restos óseos de Sus scropha y Ovis aries y fragmentos cerámicos decorados con impresiones. Una tercera etapa de habitación se relaciona con una ocupación eneolítica del abrigo.

Por su parte, en Molino de Vadico (Córdoba y Vega, 1987) la secuencia cultural documentada se

T. P., 59, n. ${ }^{\circ} 1,2002$ 
asemeja también a las anteriores, con unos niveles más antiguos encuadrables en el Paleolítico superior, un nivel epipaleolítico en el que hay una industria de tipo laminar, con restos óseos de fauna entre los que predominan las especies salvajes de conejo, cabra y, en menor porcentaje, ciervo, a la que le sigue una etapa neolítica que proporciona cerámica impresa e incisa y poca industria lítica. Asimismo, según comunicación personal de sus investigadores A. Alonso y A. Grimal (1996) también se recuperaron algunos restos de grano.

Sin que podamos descartar la posibilidad de que todos estos elementos de carácter productor hallados en contextos sin producción puedan ser una simple demostración de que el grupo de cazadores y recolectores no está aislado y no impliquen un proceso de neolitización como tal (Mercader, 1989/ 90), lo que parece desprenderse de todo ello es que en la transición Epipaleolítico/Neolítico, o dejando un tanto de lado la terminología, en la experiencia de cambio de unos modelos de vida depredadores a otros de producción no parece haber grandes rupturas, sino la pervivencia de unas formas de vida tradicionales a las que se irán incorporando elementos de "modernización" como la cerámica, alguna especie animal doméstica o el grano, lo que conducirá a la lenta aculturación de estos grupos epipaleolíticos.

Se ha postulado que el origen del arte levantino está en un conflicto de competencias territoriales, económicas y socioculturales entre las comunidades epipaleolíticas de facies geométrica y los incipientes grupos neolíticos, de tal forma que la pintura levantina surge como un mecanismo de reproducción de un modo de vida tradicional tendente a impedir la desintegración del sistema (Llavori, 1988/89). Al margen de que rechacemos la idea de que el arte levantino nazca como simple mecanismo de defensa de unas formas de vida amenazadas, ya que su contenido temático implica conceptos religiosos más amplios, sí podría ser cierto que, $a$ priori, la necesidad de tierras para cultivar obligase a la reclusión paulatina de los grupos de cazadores y recolectores en las serranías interiores, menos aptas para el cultivo.

Pero, hemos de insistir una vez más en que la evidencia arqueológica es bastante clara a la hora de mostrar una sucesión de contactos más o menos intensos entre los grupos epipaleolíticos y las primeras comunidades productoras, lo que en cierto modo viene a romper con los viejos razonamientos del evolucionismo cultural según los cuales el paso de un modo de vida depredador a otro productor constituye un cambio traumático en el que no hay vuelta atrás. Al mismo tiempo, el registro etnográfico reporta interesantes datos acerca de cómo dos o más entidades sociales y económicas en principio incompatibles conviven en un mismo territorio, integrados en un sistema más amplio y llegando a una estrecha interdependencia económica (Mercader, 1989/90), en un nuevo marco de colaboración y en el que no siempre se da el exterminio de un sistema depredador por otro productor.

Si las evidencias mobiliares otorgan una cronología neolítica antigua para el inicio de la pintura rupestre esquemática y a la vez, como hemos intentado razonar, carecemos de criterios objetivos que nos impidan establecer una comunión entre el arte levantino y las comunidades epipaleolíticas de la vertiente mediterránea, al menos ni las evidencias arqueológicas lo desmienten ni tampoco tenemos elementos de juicio suficientes para negar tal capacidad de creación plástica a los grupos epipaleolíticos, quizás podríamos pensar también que la fase de convivencia de ambos estilos, revelada por las sobreposiciones de motivos levantinos y esquemáticos, pudo corresponderse con ese periodo de cohabitación de estas comunidades epipaleolíticas y los primeros grupos productores que se deduce de los datos aportados por los yacimientos que nos han servido de referencia.

La aculturación de estos grupos de cazadores y recolectores supondrá la generalización del fenómeno esquemático y la desaparición definitiva del estilo levantino como vehículo de expresión de unas creencias asociadas a un modelo social y económico caduco.

\section{BIBLIOGRAFÍA}

Acosta Martínez, P. (1984): "El arte esquemático ibérico: problemas de cronología preliminares". Scripta Praehistorica. Francisco Jordá Oblata. Universidad de Salamanca. Salamanca: 31-61.

Almagro Basch, M. (1947): "Arte rupestre naturalista del Levante Español”. En R. Menéndez Pidal (dir.): Historia de España, I. Editorial Espasa. Madrid: 443-485.

- (1951): "La cronología del arte rupestre levantino". VI Congreso Arqueológico del Sureste de España: 67-80. Murcia.

- (1960): "Nuevas pinturas rupestres con danza fálica en Albarracín". Sonderdruck aus Festschift für Lothar Zozt. Erlangen: 13-18.

Alonso Tejada, A. y Grimal Navarro, A. (1996): El arte 
prehistórico en la Cuenca del río Taibilla (Albacete y Murcia): nuevos planteamientos para el estudio del arte levantino. Barcelona.

- (1999): "El arte levantino: una manifestación pictórica del epipaleolítico peninsular". En Cronología del arte rupestre levantino. Real Academia de Cultura Valenciana. Serie Arqueológica, 17. Valencia: 43-76.

Aparicio Pérez, J. (1977): "Pinturas rupestres esquemáticas en los alrededores de Santo Espíritu (Gilet y Albalat de Segart, Valencia) y la cronología del arte rupestre". Saguntum 12: 31-72.

Arias, P.; Calderón, T.; González, C.; Millán, A.; Moure, A.; Ontañón, R. y Ruiz, R. (1998/99): "Dataciones absolutas para el arte rupestre paleolítico de Venta de la Perra (Carranza, Bizkaia)". Kobie XXV: 85-92.

Asquerino, MªD. y LóPez, P. (1981): "La Cueva del Nacimiento(Pontones)".Trabajos de Prehistoria 38: 109-152.

Aura TortosA, J.E. (1983): "Aportaciones al estudio de La Sarga (Alcoy, Alicante)". Lucentum II: 5-16.

BALlDELlou, V. (1983): "El arte esquemático y su relación con el levantino en la cuenca Alta del Vero (Huesca)". Zephyrus XXXVI: 113-115.

BARANDIARÁN, I. y CAVA, A. (1985): "Las industrias líticas del Epipaleolítico y del Neolítico en el Bajo Aragón”. Bajo Aragón, Prehistoria V: 49-86.

- (1989): La ocupación prehistórica del Abrigo de Costalena (Maella, Zaragoza). Colección Arqueología y Paleontología. Serie Arqueología Aragonesa. Monografías 6. Diputación General de Aragón. Zaragoza.

Beltrán Martínez, A. (1968a): Arte rupestre levantino. Monografías Arqueológicas, IV. Zaragoza.

- (1968b): "Sobre la pintura rupestre levantina de un caballo cazado a lazo del Abrigo de Selva Pascuala, en Villar del Humo (Cuenca)". Miscelánea Lacarra. Zaragoza: $81-86$.

- (1970): "Algunos problemas que plantean las superposiciones de pintura en el arte rupestre levantino". XI Congreso Nacional de Arqueología (Mérida 1969): 225-236. Zaragoza.

- (1983): "El arte esquemático en la Península Ibérica: orígenes e interrelaciones. Bases para un debate". Zephyrus XXXVI: 37-41.

- (1985): "Las industrias líticas y el arte rupestre levantino". Bajo Aragón, Prehistoria V: 37-48. Zaragoza.

- (1987): "La fase pre-levantina en el arte prehistórico español". Archivo de Prehistoria Levantina XVII: 8196.

- (1998): Arte prehistórico en la Península Ibérica. Diputación de Castellón. Castellón.

- (1999): "Cronología del arte levantino: cuestiones críticas". En Cronología del arte rupestre levantino. Real Academia de Cultura Valenciana. Serie Arqueológica 17. Valencia: 7-41.

Beltrán Martínez, A. y Royo Lasarte, I. (1996): Las pinturas rupestres de la Cañada de Marco. Alcaine (Teruel). Ayuntamiento de Alcaine. Teruel.
- (1998): Las pinturas rupestres de la Cabecera del Barranco del Mortero. Alacón (Teruel). Ayuntamiento de Alacón. Teruel.

Beltrán Martínez, A. y San Nicolás del Toro, M. (1988): Las pinturas de las Cuevas de Peña Rubia (Cehegín, Murcia). Institución Fernando el Católico. Zaragoza.

BERnABEU, J. (1988): "El neolítico en las comarcas meridionales del País Valenciano”. En P. López (coord.): El Neolítico en España. Editorial Cátedra. Madrid: 131166.

BREUIL, H. (1933/35): Les peintures rupestres squemàtiques de la Peninsule Iberique. IV vols. Lagny.

Breuil, H.; Serrano, P. y Cabré, J. (1912): "Les peintures rupestres d'Espagne, IV: Les Abris del Bosque, à Alpera (Albacete)". L'Anthropologie XIII: 34-36.

Cabré Aguiló, J. (1915): Arte rupestre en España. Memorias de la Comisión de Investigaciones Paleontológicas y Prehistóricas 1. Madrid.

- (1941): "Pinturas y grabados rupestres esquemáticos de las provincias de Soria y Segovia". Archivo Español de Arqueología XLIII: 316-344.

CACHO, C. (1986): "Nuevos datos sobre la transición del magdaleniense al epipaleolítico en el País Valenciano: el Tossal de la Roca". Boletín del Museo Arqueológico Nacional IV: 117-129.

Chapa Brunet, T. (2000): "Nuevas tendencias en el estudio del arte prehistórico". Arqueoweb 2 (3) (http: www.ucm..es/info/arqueoweb).

Córdoba, B. y Vega, L.G. (1987): "Abrigo del Molino de Vadico”. Arqueología en Castilla-La Mancha. Excavaciones, 1985. Toledo: 79-85.

Criado Boado, F. y Penedo Romero, R. (1989): “Cazadores y salvajes: una contraposición entre el arte Paleolítico y el arte Postglaciar Levantino". Munibe 41: 3-22.

Dams, L. (1984): Les peintures rupestres du Levant espagnol. Picard. París.

ForTEA PÉREZ, F.J. (1973): Los complejos microlaminares y geométricos del Epipaleolítico Mediterráneo espa$\tilde{n} o l$. Memoria del Seminario de Prehistoria y Arqueología 4.

- (1974): “Algunas aportaciones a los problemas del arte levantino". Zephyrus XXV: 225-257.

- (1975): "En torno a la cronología relativa del inicio del arte levantino (avance sobre las pinturas rupestres de $\mathrm{La}$ Cocina”. Saguntum 11: 185-197.

Fortea Pérez, F.J. y Aura Tortosa, E. (1987): "Una escena de vareo en la Sarga (Alcoy). Aportaciones a los problemas del arte levantino". Archivo de Prehistoria Levantina XVII: $97-120$.

Galiana Botella, Mª F. (1992): Consideraciones en torno al arte rupestre del Bajo Ebro y del Bajo Aragón". Aragón/Litoral Mediterráneo: intercambios culturales durante la Prehistoria. Zaragoza: 447-453.

García Guinea, M.A. y San Miguel Ruiz, J.A. (1975): "Los abrigos rupestres con pintura levantina de Nerpio. Nuevos hallazgos". Sautuola I (XIV): 75-80.

T. P., 59, n. ${ }^{\circ} 1,2002$ 
Gavilán Ceballos, B. (1985): “Alisador grabado procedente de la Cueva de la Murcielaguina (Priego de Córdoba)". Ifigea II: 173-176.

- (1989): "Paralelismo entre la decoración cerámica y el arte esquemático parietal: vasija de la Cueva de la Murcielaguina (Priego de Córdoba)". XIX Congreso Nacional de Arqueología (Castellón de la Plana 1987): 229236. Zaragoza.

Grimal Navarro, A. (1995): “Avance al estudio de las pinturas rupestres de la Cueva de la Cocina y su relación técnica con el arte levantino". XXI Congreso Nacional de Arqueología (Teruel 1991): 317-326. Zaragoza.

HERNÁNDEZ PACHECO, E. (1924): Las pinturas rupestres de la Cueva de la Araña. Evolución del arte rupestre en España. Memorias de la Comisión de Investigaciones Paleontológicas y Prehistóricas 34. Madrid.

HERNÁNDEZ PÉREZ, M.S. (1992): “Arte rupestre en la región central del Mediterráneo peninsular”. Aragón/Litoral Mediterráneo: intercambios culturales durante la Prehistoria. Zaragoza: 141-159.

Hernández Pérez, M.S. y Centre d’Estudis Contestans (1982): "Consideraciones sobre un nuevo tipo de arte rupestre prehistórico". Ars Praehistorica 1: 179-187.

Hernández Pérez, M.S.; Ferrer Marset, P. y Catalá FeRRER, E. (ed.) (1988): Arte rupestre en Alicante. Fundación Banco Exterior y Diputación de Alicante. Alicante.

- (1994): L'Art Macroesquemàtic. L'albor d'una nova cultura. Centre d'Estudis Contestans. Valencia.

- (2000): L'Art Squemàtic. Centre d'Estudis Contestans. Valencia.

JORDÁ CERDÁ, F. (1985): 'El arte prehistórico de la región valenciana: problemas y tendencias". Arqueología del País Valenciano. Panorama y perspectivas. Valencia: 121-140.

Jordá Cerdá, F. y Alcácer Grau, J. (1951): Las pinturas rupestres de Dos Aguas (Valencia). Servicio de Investigación Prehistórica. Trabajos Varios 15. Valencia.

Llavori de Micheo, R. (1988/89): "El arte postpaleolítico levantino de la Península Ibérica. Una aproximación sociocultural al problema de sus orígenes". Ars Praehistorica 7-8: 145-156.

LÓPEz, P. (1988): "Repertorio de fechas de C14 para el Neolítico español”. En P. López (coord.): El Neolítico en España. Editorial Cátedra. Madrid: 419-424.

López PAyer, M.G. (1988): La pintura rupestre en Sierra Morena oriental. Universidad Complutense. Madrid.

Marcos Pous, A. (1981): "Sobre el origen neolítico del arte esquemático". Corduba Archeologica 9: 63-71.

Martí Oliver, B. (1978): "Cova de l'Or (Beniarrés, Alicante). Nuevos datos sobre el Neolítico del este peninsular". Carbono 14 y Prehistoria de la Península Ibérica. Fundación Juan March. Madrid 57-60.

Martí Oliver, B. y Hernández Pérez, M.S. (1988): El Neolitic Valencià. Art rupestre i cultura material. Servicio de Investigación Prehistórica. Valencia.
Martí Oliver, B.; Pascual Pérez, J. y Gallart Martí, M.D. (1980): Cova de l'Or (Beniarrés, Alicante). Servicio de Investigación Prehistórica. Trabajos Varios 65 (II). Valencia.

Martínez Perelló, Maar. y Díaz-Andreu García, M. (1992): "El Abrigo de la Hoz de Vicente (Minglanilla, Cuenca). Espacio, Tiempo y Forma, Serie I (5): 177 206.

Martínez SÁnchez, C. (1994): "Nueva datación de C-14 para el Neolítico de Murcia: los Abrigos del Pozo (Calasparra)". Trabajos de Prehistoria 51 (1): 157-161.

Mas CoRnellá, M. (2000): "De los cazadores recolectores del Holoceno Inicial a las sociedades productoras en Andalucía. Una interpretación a través del arte". $3^{\circ}$ Congreso de Arqueología Peninsular: 415-432. Porto.

Mateo Saura, M.A. (1991): "Las pinturas rupestres esquemáticas del Abrigo de la Fuente, Cañada de la Cruz (Moratalla, Murcia)". Caesaraugusta 68: 229-239.

- (1992): "Reflexiones sobre la representación de actividades de producción en el arte rupestre levantino". Verdolay 4: 15-20.

- (1993): "Acerca de los signos reticulares de los Cantos de Visera (Yecla, Murcia)". Yakka 4: 9-13.

- (1995): “Hay un arte paleolítico en Cantos de Visera?. Reflexiones para un debate". Yakka 6: 7-11.

- (1996): "Las actividades de producción en el arte rupestre levantino". Revista de Arqueología 185: 6-13.

- (1997/98): "Arte rupestre y neolitización en el Alto Segura". Anales de Prehistoria y Arqueología 13-14: $39-45$.

- (1999): Arte rupestre en Murcia. Noroeste y Tierras Altas de Lorca. Editorial KR. Murcia.

Mateo Saura, M.A. y Bernal Monreal, J.A. (1999): "El arte rupestre del Abrigo de Charán (Moratalla, Murcia)". Memorias de Arqueología 1993 8: 119-127.

Mateo Saura, M.A. y Carreño Cuevas, A. (1997): "Las pinturas rupestres del Abrigo del Barranco Bonito (Nerpio, Albacete)". Al-Basit 41: 33-49.

- (2000): “Aportaciones al estudio del arte rupestre en Nerpio (Albacete): los conjuntos de Mingarnao, Sacristanes y Huerta Andara". Al-Basit 44: 7-43.

Mazo Pérez, C. y Montes Ramírez, L. (1987): "La Cueva del Llop (Mazaleón, Teruel)”. Caesaraugusta 64:119. 134.

- (1992): "La transición Epipaleolítico-Neolítico antiguo en la cueva de El Pontet (Maella, Zaragoza)". Aragón/ Litoral Mediterráneo. Intercambios culturales durante la Prehistoria. Zaragoza: 243-254.

MERCADER, J. (1989/90): "Nuevas perspectivas sobre el final de la caza-recolección y los inicios de la agricultura/ganadería”. Kalathos 9-10: 47-64.

Moure Romanillo, A. (1999): Arqueología del arte prehistórico en la Península Ibérica. Editorial Síntesis. Madrid.

MuÑoz, A. (1972): “Análisis de C14 sobre muestras reco- 
gidas por el Instituto de Arqueología de la Universidad de Barcelona”. Pyrenae 8: 148-150.

Obermaier, H. (1916): El hombre fósil. Memorias de la Comisión de Investigaciones Paleontológicas y Prehistóricas 9. Madrid.

Ortego FríAs, T. (1968): "Una nueva estación de arte rupestre en el término de Alcaine (Teruel)". Simposio Internacional de Arte Rupestre (Barcelona 1966): 149-163. Barcelona.

Pericot García, L. (1942): La Cueva del Parpalló (Gandía). Excavaciones del Seminario de Investigaciones Prehistóricas de la Diputación de Valencia e Instituto Diego de Velázquez. Madrid.

- (1945): "La Cueva de la Cocina (Dos Aguas). Nota preliminar". Archivo de Prehistoria Levantina 2: 3971.

RAMOS FERNÁNDEZ, R. (1982): “Una pintura parietal en la Cueva de las Arañas del Carabasí”. Helike 1: 135-138.

RiPOll Perelló, E. (1962): "Representación de un jinete en la pintura rupestre del Cingle de la Gasulla (Castellón)". Zephyrus XIII: 91-94.

- (1968): "Cuestiones en torno a la cronología del arte postpaleolítico en la Península Ibérica”. Simposio Internacional de Arte Rupestre (Barcelona 1966): 165192. Barcelona.

- (1983): "Cronología y periodización del esquematismo prehistórico en la Península Ibérica". Zephyrus XXXVI: 27-35.

RoDANÉS, J.M. (1991): "Excavaciones arqueológicas en el Abrigo de Secans (Mazaleón, Teruel). Campañas de (1986) y (1987)". Arqueología Aragonesa 1986-1987. Zaragoza: 57-61.

Rodríguez, G. (1979): “La Cueva del Nacimiento”. Saguntum 14: 33-38.

Salmerón Juan, J. y Lomba Murandi, J. (1995): "El arte rupestre postpaleolítico". En F. Chacón (dir.): Historia de Cieza, I. Murcia: 91-115.

SARrión Montañana, I. (1980): "Valdecuevas. Estación Meso-Neolítica en la Sierra de Cazorla (Jaén)". Saguntum 15: 23-56.

Utrilla Miranda, P. (1986/87): "Nuevos datos sobre la relación entre el arte rupestre y yacimientos arqueológicos en el Valle del Ebro". Bajo Aragón, Prehistoria VII-VIII: 323-339. 